\title{
A GEOMETRIA DE TRAÇOS E SUAS CONTRIBUIÇÕES AOS ESTUDOS FONOLÓGICOS ${ }^{1}$
}

\author{
THE FEATURES GEOMETRY AND THEIR \\ CONTRIBUTIONS TO PHONOLOGICAL STUDIES
}

Eliane Pereira Machado Soares ${ }^{2}$

\section{Resumo:}

Ao longo de seu desenvolvimento, a Fonologia vem apresentando diferentes abordagens, para a interpretação dos sistemas sonoros das línguas e dos processos fonológicos, que abrangem os chamados modelos lineares e os não lineares. O primeiro deles, o modelo fonêmico, de base estruturalista. Os segundos desdobramentos do modelo clássico ou a Fonologia clássica ou ainda Fonologia Gerativa Padrão tratada por N. Chomsky e Halle, em The Sound Pattern of English (SPE), de 1968. A obra inaugurou os estudos voltados para os processos fonológicos das línguas, para os quais procuram formular regras, cujos desdobramentos podem ser apontados em teorias fonológicas atuais. A descrição e análise dos sons de uma língua e os processos fonológicos são de grande interesse para essas fonologias, dentre as quais a Fonologia de Geometria de Traços, de Clements e Hume (1995). Neste trabalho, apresentamos uma reflexão sobre essa teoria e suas contribuições para a fonologia atual.

Palavras chave: Fonologia; Geometria de Traços; Modelos não lineares.

\begin{abstract}
:
Throughout its development, the Phonology has been presenting different approaches for the interpretation of the languages sound systems and phonological processes, that involves the denominated linear and nonlinear models. The first one, the phonemic model, with a structuralist base. The second developments of the classical model or classical Phonology or even the standard Generative Phonology attended by N. Chomsky and Halle, in The Sound Pattern of English (SPE), in 1968. The work opened

$1 \quad$ Esse artigo é parte integrante da tese de doutorado "Palatais lateral e nasal no falar paraense: uma análise sociolinguística e fonológica,” (2008), orientada pela Profa. Dra. Maria do Socorro da Silva de Aragão- Universidade Federal do Ceará.

2 Universidade Federal do Sul e Sudeste do Pará, Unifesspa/Campus de Marabá
\end{abstract}

Vol. $25-$ Ano $44-n^{\circ} 1-2020$ 
studies focused on the languages phonological processes, for which seek to formulate rules, whose developments can be pointed out in current phonological theories. The sounds of a language description and analysis and the phonological processes are of great interest for these phonologies, including the Phonology of Features Geometry, by Clements and Hume (1995). In this work, we present a reflection on this theory and its contributions to the current phonology.

Keywords: Phonology; Features Geometry; Nonlinear models.

\section{Da Fonologia clássica à Autossegmental}

A Fonologia pode ser distinguida a partir de duas grandes abordagens: Os modelos lineares e o s modelos não lineares ${ }^{3}$. Os modelos lineares fonológicos têm seu desenvolvimento marcado, por um lado, pelos estudos dos sistemas fonológicos das línguas indígenas americanas, a partir da noção de fonema e distribuição complementar, tendo à frente estudiosos como E. Sapir, L. Bloomfield entre outros; e, por outro, pela Fonologia de Praga, com as contribuições fundamentais de R. Jakobson com a noção de traços distintivos.

Os modelos não lineares são assim chamados "porque suas unidades de trabalho vão além dos limites do fonema e das matrizes de propriedades. Além disto, os elementos paradigmáticos dessas unidades acabaram tendo uma organização própria, com uma hierarquia bem estabelecida." (CAGLIARI, 2002, p.118).

A Fonologia Gerativa Padrão (ou $S P E$ ) tem por foco o sistema de regras derivacionais pelas quais se relaciona a estrutura subjacente à estrutura de superfície. A contribuição fundamental da teoria pode ser caracterizada por levar em conta o traço fonológico como uma característica binária do fonema, compreendido como um conjunto de valores que se constitui sua matriz - sobre a qual as regras agem - de traços binários, não-ordenados, do tipo $[ \pm]$ cuja função é a de atribuir ao fonema um conjunto de categorias fonéticas que determinam suas propriedades físicas. Entende-se ainda que segmentos dos sistemas fonológicos das línguas se organizam em um conjunto de traços que serve para caracterizar os seus sons distintivos, formando classes naturais de sons, esses, por sua vez, se caracterizam por ter comportamento semelhante, em consequência sons e regras que atuam em processos fonológicos podem ser expressos por meio de uma forte formalização.

Essa análise, dita hoje clássica, propõe regras de formulação que convertem estruturas subjacentes em estruturas de superfície e representam a capacidade do falante de fazer generalizações sobre dados da língua. A importância e o alcance da teoria

3 Lineares: Modelo Fonêmico; Fonologia Gerativa Padrão; Fonologia Natural; Fonologia Gerativa Natural; modelos não-lineares: Fonologia CV; Fonologia de Dependência; Fonologia de Governo; Fonologia Autossegmental; Fonologia Lexical; Fonologia Métrica; Fonologia Prosódica, Teoria da Otimização (Otimalidade -TO). (Cf. CristófaroSilva, (2001), Abaurre (1993), Cagliari (2002) Bisol (1992), Mori (2001).

Vol. 25 - Ano $44-n^{\circ} 1-2020$ 
foram fundamentais aos estudos fonológicos de línguas de todo o mundo, passando por diversas reformulações, e tendo sua continuidade garantida pela sucessão de modelos interpretativos que irão propor avanços teóricos, mas ainda numa perspectiva linear ou segmental do aspecto sonoro das línguas, o que significa certas limitações.

Como lembram Abaurre e Wetzels (1992) e Wetzels (1995), a SPE não apresenta formalismo para a representação e a manipulação de propriedades prosódicas, como altura (pitch) e duração, devido considerar a relação entre segmentos e traços como bijetiva (bijectivity constraint). Assim, cada especificação corresponde a um traço e segmento. Esta concepção será superada pelos modelos não lineares sucedâneos que colocarão a interpretação da sílaba, os aspectos prosódicos e as unidades superiores à silaba como objetos de interesse da fonologia. Dentre eles, interessam diretamente ao nosso trabalho a Fonologia Autossegmental e a Geometria de Traços.

A Fonologia Autossegmental (GOLDSMITH, 1976; 1990) é uma visão que amplia os propósitos da fonologia gerativa em dois aspectos centrais: propugna-se que não há uma relação do tipo um para um (bijetiva) entre o fonema e a matriz de traços a ele associada e propõe-se uma hierarquia entre os traços distintivos. À noção de traços agrega-se a ideia de que estes são autossegmentais, o que significa que cada traço ocupa um lugar próprio exclusivo, denominado 'tier', em relação aos demais traços do sistema, operando assim de forma própria. Nas palavras de Goldsmith (1985, p. 297-8):

O que distingue a fonologia autossegmental do tipo de fonologia do Sound Pattern English é, primeiro, o desenvolvimento de uma análise fonológica multilinear, segundo a qual diferentes traços podem ser colocados em níveis distintos, sendo os vários níveis organizados por "linhas de associação" e por uma Condição de Boa Formação; e segundo, a análise de fenómenos fonológicos não tanto em função de regras de alteração de traços, como acontecia, mas antes em termos de regras que suprimem e reorganizam os vários auto-segmentos, pelo reajuste das linhas de associação.(...) Isto é, abandonamos a assunção de que as representações fonológica e fonética subjacentes consistem numa única cadeia, ou concatenação de segmentos. No seu lugar consideramos a existência de formas subjacentes e de superfície que consistem em cadeias de segmentos paralelos, dispostos em dois ou mais níveis. Os traços estão distribuídos pelos vários níveis, de tal modo que nenhum traço aparece em mais do que um nível.

A análise primeiramente faz a segmentação mínima e exaustiva dos sons, concebidos como hierárquica e linearmente ordenados, mas não necessariamente binários, que são especificados por meio de colunas de traços articulatórios ('tiers'), só depois os analisando como conjunto de traços. Com isto, pretende dar uma representação para os 
processos fonológicos que podem ocorrer numa dada língua, tais como a assimilação, dissimilação, epêntese, apagamento, harmonia vocálica, nasalização.

De fato, a não aceitação da relação bijetiva entre segmento e conjunto de traços tem consequências fundamentais para esse modelo que podem ser resumidas em três aspectos centrais: os traços que compõem um segmento podem se estender para além dele, ou seja, um traço pode envolver mais de um segmento; o apagamento de um traço não significa o apagamento de todos os traços que compõem o segmento; os traços são hierarquicamente organizados o que permite analisá-los em "tiers", o que quer dizer que os traços podem ser analisados tanto isoladamente como em conjunto.

Nessa perspectiva, as regras agem sobre os traços e não sobre a matriz. A proposta de representação consiste em diferentes linhas autossegmentais, cada uma constituindo uma sequência independente de segmentos de acordo com um procedimento no qual a segmentação horizontal precede a vertical. Tal princípio é fundamental à teoria e ao seu desdobramento na Geometria de Traços, sendo, pois, conveniente aqui apresentá-los mais detalhadamente.

\section{A Fonologia de Geometria de Traços}

A teoria postula que as representações subjacentes derivam as representações fonéticas, conforme Princípios de boa-formação; a estrutura subjacente, interna básica da sílaba tem representação em onset e rima, que são ocupados por unidades de tempo do tipo Consoante e Vogal, cuja organização na sílaba obedece a uma escala de sonoridade, definindo assim suas posições estruturais. Entende-se que as restrições de combinação e o número de segmentos na sílaba são definidos pelo Princípio de Sonoridade e Condições de Licenciamento Silábico em cada língua, da mesma forma a boa formação está sujeita ao Princípio de Não Cruzamento de Linhas de Associação e Princípio do Contorno Obrigatório.

Os Princípios de boa formação dizem respeito às condições de uma forma linguística, sendo considerada bem formada se está em conformidade com as regras universais, que dizem respeito às limitações do aparelho fonador humano, particularizadas em uma língua a partir de evidências fornecidas pelas descrições estruturais. No aspecto estritamente fonológico e no âmbito da teoria, tais princípios estão sujeitos ao Princípio de Sonoridade segundo o qual os segmentos de uma língua se organizam em uma hierarquia de som que, por sua vez, definem as Condições de licenciamento silábico estabelecendo quais segmentos sonoros podem ocupar as posições estruturais dos constituintes da sílaba (onset, rima, núcleo).

Clements (1989b, p.19) apresenta uma escala de sonoridade baseada em dois critérios, soância (relacionada aos graus de abertura) e constrição (relacionada aos traços de articulação): assim, para os segmentos, quanto menor for a soância maior a constrição

Vol. 25 - Ano $44-n^{\circ} 1-2020$ 
(caso das obstruintes) e, inversamente, quanto maior a soância menor a constrição (caso das vogais), como mostra figura a seguir"

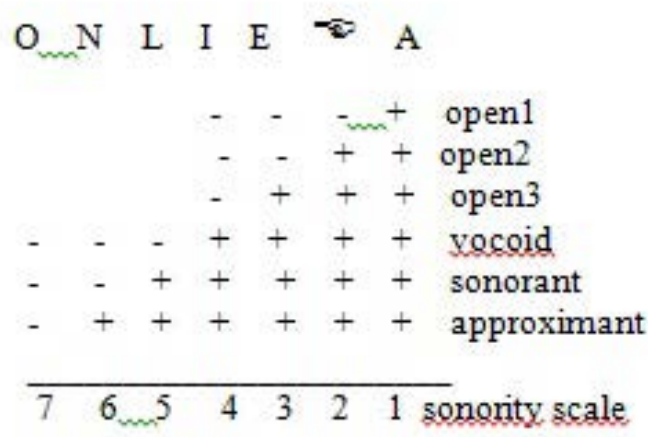

FIGURA 01: Escala de soância e constrição segundo Clements (1989) Fonte: Clements $(1989$, p. 24$)$

Essa mesma escala de sonoridade pode ser expressa de modo mais geral como no quadro abaixo (cf. Silva, 1997, p.42):

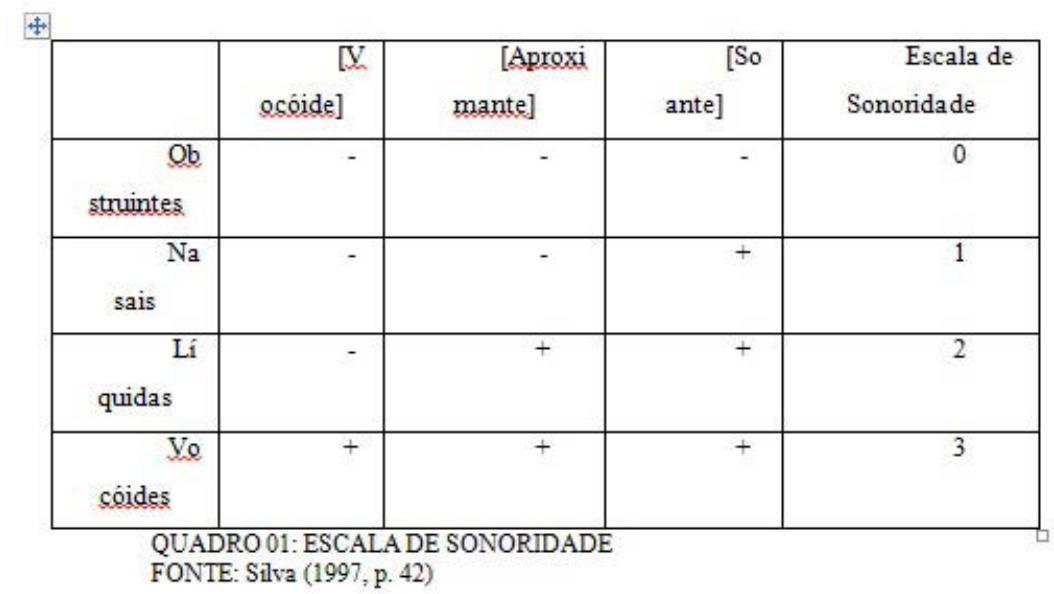

Indica-se deste modo que, num dos polos, os sons com maior constrição e menor soância são as obstruintes e, no outro, os sons de menor constrição e maior soância são as vogais. Aceita-se, de acordo com esta escala, que C (consoantes) e V (vogais) são categorias, constituindo-se em unidades temporais (Clements e Keyser, 1983). Os constituintes silábicos são o Onset e a Rima: o Onset (ataque) associa-se à Consoante, precedendo a Rima, que se constitui de Núcleo, uma posição obrigatória, associada à Vogal seguida pela Coda, uma posição opcional, que se associa à Consoante. Portanto, o esqueleto (skeleton), a estrutura básica da sílaba tem a seguinte representação:

$4 \mathrm{O}=$ obstruent, $\mathrm{N}=$ nasal stop, $\mathrm{L}=$ liquid, $\mathrm{I}$, high vocoid, $\mathrm{E}=$ upper mid vocoid, $\mathrm{E}=$ Lower mid, $\mathrm{A}=$ low vocoid.

Vol. 25 - Ano $44-n^{\circ} 1-2020$ 


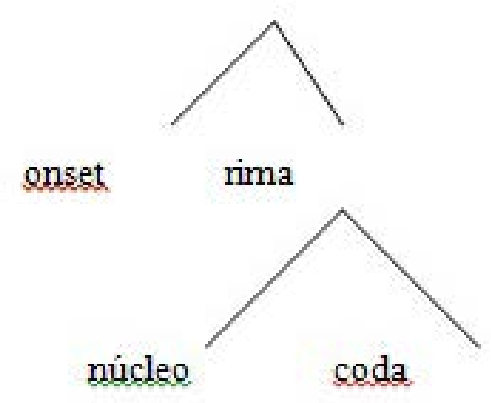

Tendo em vista que os auto-segmentos são ligados a suas unidades segmentais por linhas de associação, estabelece-se pelo Princípio de não-cruzamento de linhas de associação que linhas de associação, que ligam dois elementos aos seus tiers, não podem se cruzar.

$(02)$

a.

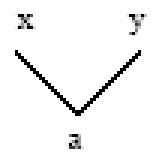

b.

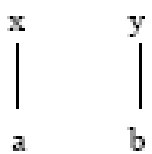

c.

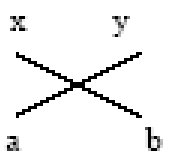

Pelos esquemas representados em (a) e (b), temos a representação de boa formação, ao passo que em (c) temos uma sequência mal formada. Esse princípio relaciona-se a fenômenos de assimilação em sequências como (a) e (b) e está diretamente relacionado ao Princípio de Contorno Obrigatório ( $\mathrm{PCO}$ ou, em inglês, $\mathrm{OCP}$ ) pelo qual se proíbe segmentos idênticos adjacentes num mesmo tier, evitando-se com isso sequências mal formadas, o que em termos de processos fonológicos resulta, por exemplo, em dissimilação ou supressão.

Como desdobramento da teoria autossegmental, a Geometria dos Traços (Clements, 1985, 1991; Clements e Hume, 1995) entende que os traços que constituem os segmentos sonoros têm uma organização geométrica: eles estão ligados direta ou indiretamente a um nó de raiz que corresponde à unidade temporal de um só segmento, Consoante (C) ou Vogal (V), que desencadeia uma estrutura hierárquica.

A representação leva em conta aquelas propriedades físicas que atuam tanto para caracterizar os segmentos, como classes naturais de sons, quanto os processos que podem envolvê-los, em qualquer língua, nesse caso, pelo desligamento e associação de linhas que ligam os autossegmentos na estrutura arbórea na qual se acham hierarquicamente dispostos. Quer-se refletir, de modo mais simples e natural possível, somente os sons passíveis de realização pelo ser humano e os processos fonológicos nas línguas, dos quais 
Cagliari (1997, p. 20) aponta como os mais importantes a assimilação (espraiamento), desligamento, fissão, fusão, além de outros, tais como mencionamos anteriormente. Além disto, outras noções também fazem parte da abordagem geométrica, como mapeamento de contexto, domínio, gatilho, filtro etc ${ }^{5}$.

A análise postula que vogais e consoantes partilham dos mesmos traços, modo de articulação e propriedades laríngeas, ou seja, aqueles que definem classes maiores, não havendo traços n-ários e não-binários; sob esse ponto de vista, as categorias mais altas ou supralaríngeas são mais independentes do que as categorias mais baixas, laríngeas (o que permite distinguir diferentes tipos de processos fonológicos de assimilação e dissimilação, total ou parcial). A proposta relaciona-se, portanto, ao mecanismo de produção de sons. A representação dos sons (e dos processos), ao invés de matrizes de traços, é feita por meio de uma estrutura arbórea, ramificada: "Nessa abordagem, segmentos são representados em termos de configurações de nós hierarquicamente organizados cujos nós terminais são valores de traços e nós intermediários representam constituintes" (Clements e Hume, 1995, p. 249). ${ }^{6}$

A estrutura a seguir é a representação geométrica genérica dos segmentos sonoros inicialmente proposta por Clements (1989a; 1991):

Já na figura seguinte, vemos apresentação desse esquema adaptado a consoantes e vogais.

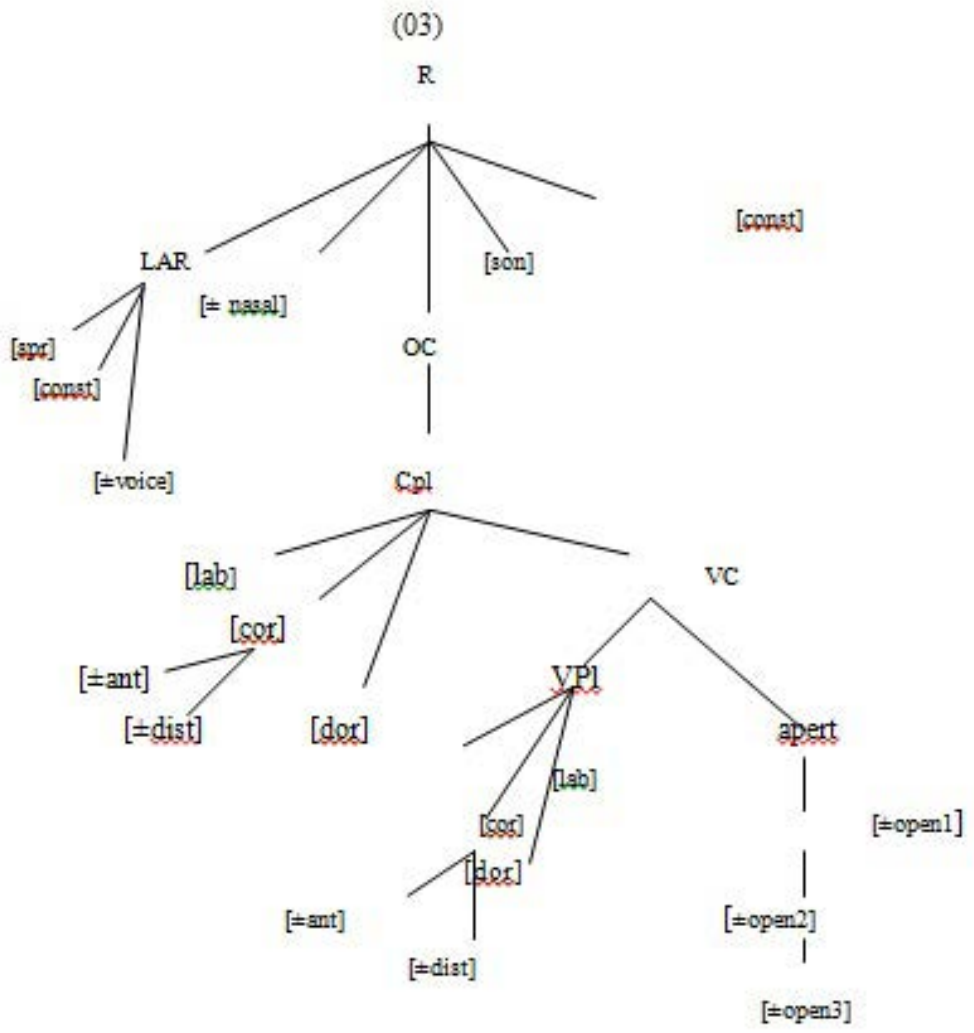

Vol. 25 - Ano $44-n^{\circ} 1-2020$ 
(01) Consoantes

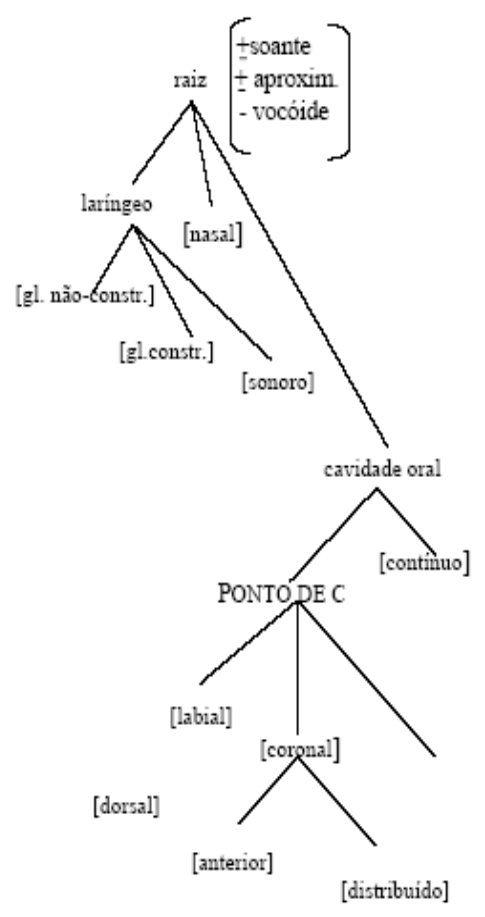

(02) vogais

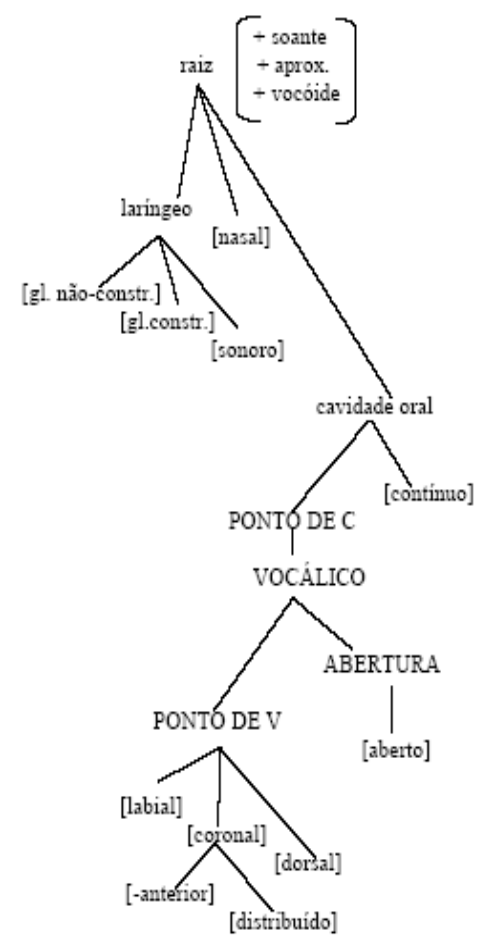

O esqueleto representa a linha do tempo no qual os segmentos sonoros da fala se sucedem. $\mathrm{O}$ elemento $\mathbf{X}$ na estrutura arbórea representa uma unidade abstrata de tempo. A ele se acha imediatamente associado o Nó de Raiz (R) que é propriamente o segmento fonético, sob esse nó estão os Nós de Classe, que são intermediários e dominam os Nós Terminais que são os próprios traços fonológicos indicados pelos colchetes.

Conforme a estrutura indica, e Clements e Hume (1995) afirmam, as regras fonológicas são naturais quando se aplicam a traços individuais dominados pelo mesmo nó de classe, isto é, os traços funcionam de forma solidária, em dois processos principais: desligamento de uma linha de associação (apagamento) ou espraiamento de traços (assimilação total: se processa no nó de raiz, levando o nó para outra posição; assimilação parcial: quando ocorre nos demais).

A concepção hierárquica da organização de traços leva Clements e Hume (1995) a proporem uma classificação para os tipos de segmentos possíveis nas línguas, são eles: os segmentos simples (simple), complexo (complex) e de contorno (contour segment), definidos da forma como se segue:

Segmentos simples: são caracterizados por associar-se a um nó de raiz, tendo, portanto, uma única unidade de tempo, e apresentando um traço de articulação oral. É o caso de vogais e consoantes simples. 
$(05)$
a.
b. $\quad \mathrm{I}_{\mathrm{r}}^{\mathrm{x}}$
[t]

Segmentos complexos: apresentam também um nó de raiz, como os segmentos simples, porém apresentam dois traços de articulação oral, como uma articulação primária consonantal e uma articulação secundária vocálica. Exemplo disto em PB é a realização [:] em final de sílaba, que ocorre em algumas pronúncias do Brasil.

(06)

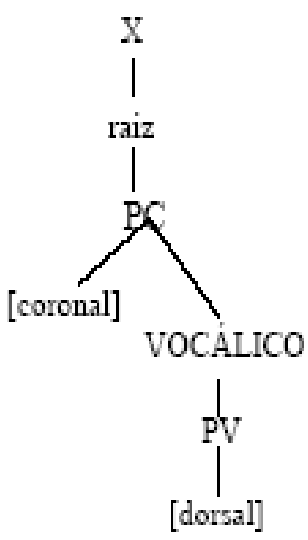

Segmentos de contorno: apresentam dois nós de raiz ligados a uma mesma unidade de tempo, o que lhe confere diferentes traços. Exemplo disto são as realizações [tS] e [dZ] diante de vogal anterior alta, como em grande parte dos dialetos brasileiros.

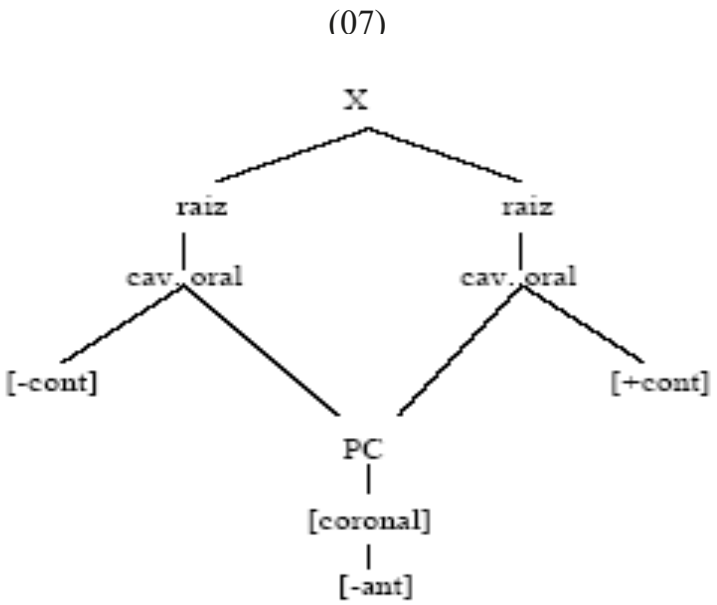

Consoantes geminadas e vogais longas apresentam duas unidades de tempo associadas a um nó de raiz. 


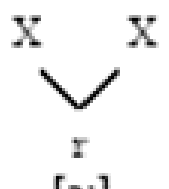

[a:]

Assim, esses conceitos de segmentos orientam a representação geométrica dos sons de uma língua e explicam os processos fonológicos pelo ligamento e desligamento de traços.

\section{Considerações finais}

A Fonologia Gerativa Padrão, inaugurada pela obra The Sound Patterns English (SPE), de N. Chomsky e M. Halle (1968), propiciou o desenvolvimento da fonologia a ponto de dar conta das propriedades dos sistemas fonológicos das línguas em geral, partindo de dados reais de línguas particulares. Desdobramentos posteriores deram surgimento às fonologias ditas não lineares que enfatizam os processos fonológicos existentes nas diferentes línguas, sendo a Geometria de Traços um dos estudos mais recentes.

Como vimos, a preocupação dessa Fonologia é o a de fornecer generalizações sobre os processos fonológicos das línguas, a partir da produção dos sons possíveis pelo aparelho fonador humano, segundo uma "geometria" que descreve essas possibilidades articulatórias e entram no funcionamento das regras que dão origem aos processos.

É importante dizer que a Geometria de Traços faz a auto segmentação de traços subespecificados, o que significa que só são representados os traços estritamente necessários para se definir os elementos fonológicos que se quer especificar, eliminando traços considerados óbvios ou redundantes. Entretanto, há discussões teóricas de autores Goldsmith (1995), entre outros, sobre a questão da especificação ou subespecificação, que envolvem o valor dos traços e quais traços podem ser representados, tendo em vista não somente uma escolha do tipo binária entre [+] e [-], mas também do tipo monovalente/ privativa entre $[+]$ e $[\mathrm{P}]$, essa última considerando que as regras fonológicas atuam a partir de traço $[+]$ nas diferentes línguas.

A teoria busca representar formas e processos possíveis nas línguas humanas, a partir de princípios fornecidos por evidências linguísticas e descrições estruturais. A busca pela superação de descrições arbitrárias confirma-se pela relação estabelecida entre os princípios que norteiam a teoria e a anatomia do trato vocal e os aspectos acústicos dos segmentos sonoros.

Essa abordagem se constitui em uma importante contribuição teórica e prática para compreensão do comportamento dos segmentos sonoros de uma língua, sejam eles fenômenos variáveis ou de aquisição da linguagem falada. 


\section{Referências}

ABAURRE, Maria Bernadete M. Fonologia: a gramática dos sons. Revista de Letras 5. Santa Maria: UFSM, 1993.

ABAURRE, Maria Bernadete M. e WETZELS, Leo W. Sobre a estrutura da gramática fonológica. Cadernos de Estudos Lingüísticos. Campinas, n.23, p.5-18, Jul/Dez., 1992. BISOL, Leda. Aspectos da fonologia atual. São Paulo: Revista Delta, vol. 8, n. 2, 1992. 263-283

BISOL, Leda; BRESCANCINI, Cláudia Regina. Fonologia e Variação: recortes do português brasileiro. (org.) Porto Alegre: EDIPUCRS, 2002.

CAGLIARI, Luís Carlos. Processos fonológicos do português brasileiro interpretados pela fonologia de geometria de traços. Campinas, São Paulo: Edição do Autor, 1997.

CAGLIARI, Luís Carlos. Análise fonológica: introdução à teoria e à prática, com especial destaque para o modelo fonêmico. Campinas, São Paulo: Mercado de Letras, 2002.

CALABRESE, A. Palatalization processes in the history of romance languages: a theoetical study. In: CALABRESE, A. (Ed.) Romance phonology. Doctoral Programme in Romance philology. Budapest: L. Eötv“os University, 1996, p. 65-83.

CHOMSKY , Noam, HALLE Morris. The sound pattern of English. Originally published: New York: Harper \& Row, 1968. (First MIT paperback edition, 1991).

CLEMENTS, George. The geometry of phonological features. Phonology Yarbook 2, 1985 , p. $225-252$.

CLEMENTS, George. A unified set of features for consontals and vowels. Paris, France: Institute de Phonétique, 1989a.

CLEMENTS, George. On the representation of vowel heigth. Paris, France: Institute de Phonétique, 1989b.

CLEMENTS, George. Place of articulation in consonants and vowels: a unified Theory. Paris, France: Institute de Phonétique, 1991.

CLEMENTS, George. HUME, Elizabeth. The internal organization of speech sounds. In: Goldsmith, John. The handbook of phonology theory. Cambridge: Blackwell, 1995, p. 246-306. 
GOLDSMITH, John. Autossegmental phonology. Bloomington: Indiana University Linguistic Club, 1976.

GOLDSMITH, John. Os objectivos da fonologia autossegmental. In: MATEUS, M. H. Mira. Novas perspectivas em fonologia. Lisboa: Laboratório de Fonética da Faculdade de Letras de Lisboa, 1985.

GOLDSMITH, John. The handbook of phonological theory. Oxford: Blackwell Publishers, 1995.

MORI, Angel Corbera. Fonologia. In: Mussalim, Fernanda, Anna Christina Bentes (orgs.). Introdução à Lingüística: domínios e fronteiras. São Paulo: Cortez, 2001.

SILVA, Eudênio Bezerra. A substituição da soante palatal /'/: uma representação nãolinear. Dissertação (Mestrado em Lingüística) - Universidade Federal de Pernambuco. Recife, 1997.

WETZELS, W. Leo. Estudos fonológicos das línguas indígenas brasileiras. Rio de Janeiro: Editora UFRJ, 1995. 